\title{
Daechuri as Symbolic Battleground: Failure to Integrate Divergent Frames for Conflict Interpretation
}

\author{
Hyang-Won Kwon*
}

\begin{abstract}
This study examined how government negotiators' and opponents' different frames for construing others' motivations prevented a settlement and intensified the Daechuri policy conflict over appropriation of land for a military base. Although communication- and consensus-based processes have been acknowledged as useful methods of conflict resolution, the issue of how participants' divergent definitions and interpretations of the situation may inhibit effective communication has rarely been empirically examined. Employing frame analysis, this study explored how two parties' motivations and issue interpretations were persistently mismatched over time without reaching consensus. The results revealed that government negotiators tended to oversimplify opponents' motivations as being economically driven, while they were in fact more complicated. These results suggest that communicative negotiation will not likely be conducive to effective conflict resolution unless it is based on thorough understanding of the situation.
\end{abstract}

Keywords: policy conflict, frame analysis, communicative resolution, Daechuri

\section{INTRODUCTION: THE DAECHURI CONFLICT AND COMMUNICATION BREAKDOWN}

On Thursday, May 4, 2006, a massive police operation was launched by the Korean government to evict residents and other protesters from the future site of U.S. military bases in the country. The operation entailed physical confrontation between police and protesters, and regrettably resulted in violent confrontations, injuries, and arrests.

\footnotetext{
* Hyang-Won Kwon is a doctoral candidate in the Sol Price School of Public Policy at University of Southern California. His research interest includes, but not limited to, governing boards of public sector organizations, network analysis, organization theories, and mixed methods design of various sorts. E-mail: hyangwon.kwon@usc.edu
}

Manuscript received October 22, 2012; out for review October 23, 2012; review completed November 14, 2012; accepted November 27, 2012.

The Korean Journal of Policy Studies, Vol. 27, No. 3 (2012), pp. 27-45.

(C) 2012 by the GSPA, Seoul National University 
Considering that Korea was generally thought to have achieved a complete transition to structural democratization (Park, 1991), the event came as a surprise. It was reportedly a result of failed negotiations between the government and opponents in conflict over relocation of U.S. military bases in the local area called Daechuri (Yoo, 2006). Although formal negotiations were undertaken, agreement was not reached. Prolonged stalemate then drove the authorities to exert physical power over the protesters to end the standoff.

During policy controversies, social debates, divergent beliefs, and conflicting interests are not uncommon (Charalambides et al., 2005; Quirk, 1989). However, cases in which physical confrontation is used to resolve the conflict are rare in liberal democratic countries like Korea (Adams et al., 2003). Some scholars have pointed to government authoritarianism or the absence of institutions for negotiation through communicative interactions as primary reasons (Ahn, 1990; Hong, 2012), while others have postulated that self-interested local residents' greed for more monetary rewards prevented a settlement and led authorities to exert physical power (Yoo, 2006). Neither argument fully explains this particular case, because government authorities had taken formal steps of communicative negotiations persistently throughout the period. In addition, the opposition was highly diverse and made up of a multitude of movement groups, religious entities, social protesters, and local residents. This suggests that the conflict was not merely a battle over land between greedy residents and an authoritative government. It was rather a manifestation of high-stakes conflict (Wilson, 1997) imbued with more subtle, complicated, and intertwined meanings.

Intractable policy conflicts with intertwined meanings and motivations are likely to reflect systematic biases in how negotiators define the situation (Weick, 1988). The government's negotiators may have deviated from rationality within the bargaining context, as their interpretations of the issues are not in accordance with the opponents' interpretations. Admittedly, resolutions of conflict through communicative interactions are better facilitated by "interactive integration" (O'Reilly, Caldwell, \& Barnett, 1989) or "mutual agreement" (Amason \& Sapienza, 1997) on definitions. Given that the interactions were not conducive to effective negotiation, but rather intensified the conflict, it seems reasonable to assume that the two parties failed to integrate their divergent issue definitions, motivations, and interpretations. This failure may well have caused negotiations to fail.

This study employed frame analysis (Benford, 1993; Benford \& Snow, 2000; Goffman, 1974) to investigate how government negotiators stereotyped opponents to define the situation succinctly, and how the two sides' frames diverged (and, on rare occasion, converged) over time, in order to examine how negotiator bias may have prevented effective communication and exacerbated the conflict. Drawing on the 
notion of "linguistic turn" (Alvesson \& Karreman, 2000), it employed Goffman's (1974) method of frame analysis with the aid of ATLAS.ti (http://www.atlasti.com) qualitative data analysis software that provides analytic functions including coding, clustering, content analysis, and statistical inferences.

The paper is organized as follows. First, a brief description of the Daechuri policy conflict is provided and its symbolic meaning is discussed. Next, the theoretical basis of the study, particularly regarding communicative resolution and frame analysis, is outlined. Methods of data collection and analysis are then described, followed by findings from textual analysis and a discussion of study results.

\section{CONTEXT: DAECHURI AS SYMBOLIC BATTLEGROUND}

\section{Background}

Daechuri and the surrounding land near Pyeongtaek in Korea was declared government property with the intent to relocate US military bases from Seoul in August 2004. The decision was based on a plan outlined by US President Bush on November 11, 2003, for restructuring US military bases around the world (Rumsfeld, n.d.). The location of foreign military forces in Korea's capital had also stimulated public debate over relocation to rural areas. Thus, government authorities had searched for a new site for US military bases, and chose Daechuri and nearby communities. The implementation of this decision met resistance from local residents to the seizure of their homes and lands; about 535 households and 1,372 residents faced eviction. To resolve the conflict, authorities opened negotiations with the residents on economic compensation. However, despite these negotiations, the conflict intensified and the parties failed to reach agreement.

When the government launched a police operation to forcibly evict the opponents, the conflict had dragged on for years and gained national attention. At first, popular media described the situation as a typical conflict over economic rewards for land seizure, but later the region became a symbolic battleground in which a multitude of social, political, environmental, and religious groups formed a collective to resist the authorities.

To place the situation into a social agenda and generate support from the public at large, these groups carried out a set of strategic actions-such as press conferences, candlelight vigils, media interviews, and ongoing negotiations with government- to link the conflict to more profound symbolic meanings beyond economic benefits for local people. However, these points were not well taken by government negotiators, 
and large and small physical conflicts occurred. After prolonged and unresolved conflict, the authorities carried out vicarious administrative execution accompanying physical actions to remove opponents from the location in May 2006.

\section{Daechuri as Symbolic Nexus}

The government's efforts to negotiate and persuade did not result in the intended consequences. A chorus of opponents' voices pointed out government negotiators' misinterpretation of the situation. To them, the conflict was a symbolic manifestation of much larger social struggles regarding anti-nationalism, environmental protection, social justice, procedural democracy, religious beliefs, and labor issues (McBeth \& Shanahan, 2004; Wilson, 1997). This made Daechuri a "symbolic nexus" (Williams et al., 1992), a battleground where diverse elements of social struggle were consolidated and represented. In this way, it bears a symbolic meaning beyond the local economic issues that sparked the conflict.

Since these points were not addressed by the government's negotiators, the efforts for communicative resolution did not reach consensus (Andranovich, 1995) or integration (Weick, 1993). This suggests that addressing the profound social meanings embedded in conflict is as critical for effective resolution as economic compensation (Corvellec \& Risberg, 2007; Fligstein, 1997). Addressing these meanings requires skillful management of communications as the meanings are not readily visible or measurable (Edelman, 1971; Smircich, 1983).

This raises the question of how the negotiators perceived the motivations and meanings of their opponents, and whether the negotiations resulted in integrative convergence of issue interpretation between the two parties. Empirical tests of opponents' claims about negotiators' misinterpretations were never conducted. It will be fruitful to examine how divergent points of view in construing issues prevented a settlement of the conflict (Benford, 1993; Dutton \& Dukerich, 1991). Deeper understanding of this issue would provide meaningful implications for communicative resolution, which is seen as a useful methodology for policy conflict resolution.

\section{THEORETICAL BASIS: COMMUNICATIVE RESOLUTION AND FRAME ANALYSIS}

\section{Communication as Resolution}

Communication or dialogue has been recommended as a substantive solution to intractable policy conflicts (Benford, 1993; Jeon, 2001; Nelson \& Brown, 1993). 
Opponents in conflict use communication to increase focus, unity, and a positive image for their points of view (Rouleau, 2005). When communication is successful, it is expected that opponents seek out a way to reduce their divergent points of view and to reach a mutual agreement or consensus with which both parties are fairly satisfied (Drake \& Donohue, 1996). This implies that communication has a certain degree of functional utility in resolving policy conflicts (Alvesson \& Karreman, 2000; Astley \& Zammuto, 1992). This has been critically appreciated and adopted in designing policymaking processes, as evidenced by movements toward alternative dispute resolution, a set of consensus-based processes that use collaborative decision-making techniques (Kim, 2009), including citizen participation (Ahn 1990; Bingham, Nabatchi, \& O'Leary 2005), civic engagement (Bogason \& Musso, 2006), and collaborative governance (Moe, 2001). At the heart of such movements lies an attempt to institutionalize communication between potential opponents over policy decisions to forestall conflict and thereby to reduce social costs.

Nevertheless, communication can fail. Since communication in conflict often takes the form of strategic bargaining interactions, it is often difficult to find a point at which both parties are satisfied (Hill \& Carley, 1999). As conflicts are the outcome of divergent interests and characterizations or perceptions of the issues in dispute, integration of such divisions requires strategic agility in managing communication (Imperial, 2005; Provan \& Kenis, 2008). In intractable policy conflicts, the worst-case scenario is that communication failure leads to intensified conflict, distrust, and resentment (GoldenBiddle \& Rao, 1997). It follows that strategic aspects of communication need more critical appreciation and examination, as they will have practical significance in conflict situations.

Previous research has identified some reasons for communication failures, including systematic biases in conveying meanings through dialogue (Perloff \& Persons, 1988), incompatible values with little chance of convergence (Foreman \& Whetten, 2002), mismatches between different definitions or interpretations of the situations (Moynihan $\&$ Pandey, 2008), and problematic negotiating behaviors (Cacioppo \& Berntson, 1994).

In the case of Daechuri, given that legally legitimate steps were taken to promote communication between the opposing parties for a fairly long time, the police operation and violent confrontation may be thought to be a result of communication failure. In that it ended up with a highly intensified policy conflict involving physical confrontation and forceful eviction, dialogue in this case did not function effectively as a method of conflict resolution. This raises the question about the reasons communications broke down and failed to reach a consensus. Since successful communication in policy conflicts requires a high level of negotiation skills, the opponents may have lacked or overlooked certain tactics for mobilizing consensus. 


\section{Frame Analysis}

One of the most analytically useful strategies for analyzing communication is frame analysis, which refers to the examination of meanings in communicative interactions with a focus on salient frames used in textual representations (Fiss \& Hirsch, 2005; Goffman, 1974). Communication is essentially carried out by language, and language takes the form of spoken or textual representations. Frame analysis assumes that such representations reflect the perception of reality as well as attitude-shaping behaviors (James, 1950). In representing one's perception or attitude through language, meanings with a more salient focus are thought to be attended by more frequent or more emphatic language (Berger \& Luckman, 1966). Frames point to such more salient language as epitomizing one's dominant perception or attitude. Frame analysis investigates the ways in which people construe or construct reality. Not only as a useful methodology but also as a slogan for the linguistic turn of social sciences (Alvesson \& Karreman, 2000), frame analysis has gained popularity, especially in media and management studies (Fiss \& Hirsch, 2005; Miller, 1997; Nelson, Clawson, \& Oxley, 1997; Tucker, 1998).

Applying the concept of frame analysis to policy conflicts highlights the divergent points of view through which each party construes reality. In frame analysis, convergence of frames is associated with opponents reaching substantive agreement, and divergence with the opposite. When parties to a conflict communicate, they generally select frames with which to define, construe, and convey their issues. Such frames interact and are negotiated through communicative processes. Convergence is generally regarded as the outcome of successful communication (Luhmann, 1995, 2000). Thinking of conflict resolution as the outcome of interaction implies that tracking frames in an interaction can demonstrate how communications diverge or converge over time to resolve framing disputes. As disputants tacitly negotiate frames during negotiations, each frame serves as a proposal to approach the issues in a particular manner. Exchanges of such proposals are intended to strategically mobilize consensus through symbolic representation (Sewell, 1997).

Applying framing analysis to the Daechuri conflict could help to identify potential systematic biases in the negotiation process (Neale \& Bazerman, 1985), particularly in the interpretation of issues, that may not be obvious otherwise.

\section{Theoretical Summary and Research Questions}

Frame analysis enables a researcher to empirically highlight how one uses language to construct and stereotype meanings in social contexts (Goffman, 1973, 1974, 1983; 
Levi-Strauss, 1974). Applying this approach to the study of policy conflict is useful in investigating how negotiators perceive the motivations or meanings of others (Nelson \& Brown, 1993). Given the argument that the Daechuri conflict was intensified by the two parties' divergent interpretations of the situation, it can be helpful to empirically test how divergent or convergent the two parties' interpretations of the situation were and how the negotiations contributed to or disrupted integrative convergence of the two issue frames.

\section{METHODS}

\section{Design}

So as to tap into the interpretation and meaning systems of the actors involved in the conflict, this study was fundamentally qualitative and interpretative in its approach. As discussed above, it employs frame analysis to examine the dialogue and communicative frames of the two parties to the conflict and determine whether they became convergent or divergent over time as a function of communication.

As part of the frame analysis, coding on textual data was conducted. Frames accrued from coding processes usually reduce complex issues to one or two central aspects (Nelson \& Brown, 1993), and this reduction facilitates analytic clarity regarding how an issue is construed. Drawing on verbal and visual materials that convey the motivations and meanings of the conflict, relevant codes were thematically identified and classified using ATLAS.ti analysis software.

Data on the frames of the government negotiators and their opponents with regard to motivations and issue interpretations were collected, organized, and compared, and the percentage of frame convergence was calculated for each phase of the conflict using content analysis. Bilateral coding was employed, treating the opposition as a collective with a cohesive agenda rather than as a multitude with diverse agendas. In fact, the opposition was characterized by solidarity, and various entities-including local residents, supporter groups, and movement organizations - acted under a coherent leadership in a coordinated manner. Thus, the overall structure of the conflict was bilateral.

\section{Data, Transcripts, and Coding}

The investigation drew on a variety of documents including newspaper articles, public statements, interviews, and visual documents. Extensive textual representations 
by both sides were aggregated. These were supplemented by transcripts of videos that dealt with the issue in depth - two TV programs and one independent documentary, War in Daechuri. Content analysis was carried out on this material using ATLAS.ti version 6.2. Particular attention was paid to public statements and media representations (for example, interviews), because those sources offered substantive information about the primary issues of the conflict (Bartels, 1993). This approach was informed by previous studies on agenda-setting and the priming effects of media representation (Iyengar \& Kinder, 1987; Jacobs \& Shapiro, 1994; McCombs \& Shaw, 1972). The analysis covered the duration of the conflict, about four years-from 2004 to 2007.

The texts were read and analyzed using a combination of thematic analysis (Braun \& Clarke, 2006) and content analysis (Suddaby \& Greenwood, 2005). Thematic analysis is a method for identifying, analyzing, and reporting patterns of themes within data (Braun \& Clarke, 2006). It analyzes rich textual data and generates a summative report through categorization with regard to salient research themes. For example, it can be used in medical research to identify types of reactions of patients to chronic illness based on transcribed interviews. Given that themes succinctly epitomize patterns embedded in textual data, they are highly resonant with frames. Indeed, in analytic contexts frames are almost synonymous with themes, as both focus on coding to systematically reduce texts into summative patterns (Holton, 2007; Hsieh \& Shannon, 2005).

This study used thematic analysis with a focus on two dimensions of frames (Fischer, 2003): identity frames and characterization frames. An identity frame is the way a group uses language to construct its identity. In the case of Daechuri, the identity frame was equated with the motivations of opponents and government negotiators. A characterization frame is the way a group uses language to stereotype others. In effect, identity frames and characterization frames relate to how conflict participants perceive themselves and others.

To trace how the identity and characterization frames of both parties changed over time as a function of communication, phase-mapping of frame convergence was conducted by summing converged frames and dividing that number by the number of total frames. To count total frames, simple content analysis on the results of thematic analysis was conducted with the aid of ATLAS.ti. The results were dissected into eight phases based on the most dramatic events in the Daechuri policy conflict-defined as the events that either received the most media attention or caused the greatest influx of external supporters into the area. The events include press conferences, mass rallies, violent confrontations, and massive media reporting. Since the conflict dragged on for over three years, it is challenging to determine the most important turning points. This study focused on the most dramatic events, defined as those remarkable enough to be 
Table 1. Eight Phases of the Daechuri Policy Conflict

\begin{tabular}{c|r|l}
\hline Phase & Period beginning & \multicolumn{1}{c}{ Description } \\
\hline 1 & April 20, 2003, to January 3, 2004 & Emergence of conflict \\
\hline 2 & February 11, 2004 & First press conference, issue agenda spread \\
\hline 3 & May 29, 2004 & First mass rally \\
\hline 4 & May 14, 2005 & Web site launched \\
\hline 5 & July 10, 2005 & Violent confrontation, urgent press conference \\
\hline 6 & December 11, 2005 & Influx of external supporters \\
\hline 7 & February 12, 2006 & Wide public recognition of social agenda \\
\hline 8 & May 4, 2006 & Police operation, violent confrontation \\
\hline
\end{tabular}

recognized by the public via media. Eight events were chosen as defining the start of a new phase of the conflict (table 1).

Along with the eight phases, the researcher kept track of thematic commonality with regard to how the government and the opponents construed their own and the other side's motivations. In the process of coding, summative content analysis (Hsieh $\&$ Shannon, 2005) was employed. This is distinct from other approaches, such as conventional content analysis and directed content analysis, in that it focuses on keywords identified before and during data analysis (table 2). Only themes (or frames) related to motivations were counted and coded. Since this study aimed to summarize and compare the results of thematic analysis on a higher level of abstraction, the elements or themes of analysis were counted and reported in a phase-mapping summary report with numerical representation (Gioia \& Thomas, 1996).

\section{Three Types of Content Analysis}

- Conventional content analysis begins with observation. Keywords are defined during data analysis and are derived from the data.

- Directed content analysis begins with theory. Keywords are defined before and during data analysis and are derived from theory or from existing research findings.

- Summative content analysis begins with the identification of keywords. Keywords are identified before and during data analysis and are based on the researcher's interests or a literature review. 


\section{FINDINGS}

\section{Descriptive Statistics}

A total of 2,036 utterances pointed to the motivations for conflict participation by either the government or the opponents. Common motivations can be described with the following codes or keywords: land sovereignty (the most frequent), property rights, monetary rewards, agriculture, life, the national interest, anti-nationalism, antiwar views, and unity. These are described in more detail below.

- Land sovereignty points to a symbolic tie between local residents and the land. Residents are mostly local farmers whose families have lived on the land for generations. Thus, the land to them has a symbolic meaning that goes beyond its value as farmland - it is a critical habit or symbolic nexus that gives a sense of home or family (Wilson, 1997).

- Property rights means the legally defined right of property owners to live on their land without disturbance or obstruction. When the authorities are able to affect the lives of residents without their consent, property rights might not be well protected or secured.

- Monetary rewards involve compensation for eviction. Assuming that eviction is unavoidable, those who are evicted should receive a reasonable monetary compensation.

- Agriculture as a motivation reflects the fact that most Daechuri residents were farmers with a limited education and few job skills outside of farming, which made them highly reluctant to be moved to urban areas where they might not be able to get a good job.

- Life as a motivation frames residents as living organisms who consider the land as their primary habitat and believe that the military bases will destroy that habitat.

- National interest reflects the view that this value should be placed before wellbeing of individuals.

- Anti-nationalism rejects the point of view represented by national interest.

- Anti-war views object to the existence of military bases per se, locally or globally.

- Unity among like-minded social movement groups, while not directly related to the core theme of the conflict, was an important motivation for participation in the Daechuri protests.

Reliability of coding was estimated across a subsample of 500 utterances using Cohen's Kappa (Folger, Hewes, \& Poole 1984). The resulting statistics were generally found to be within an acceptable range of reliability (table 2). 
Table 2. Code Frequency and Reliability

\begin{tabular}{l|c|c}
\hline Code (motivation) & Frequency & Reliability (Cohen's Kappa) \\
\hline Land sovereignty & 782 & 0.76 \\
\hline Property rights & 323 & 0.83 \\
\hline Monetary rewards & 475 & 0.86 \\
\hline Agriculture & 121 & 0.79 \\
\hline Life & 98 & 0.73 \\
\hline National interest & 85 & 0.69 \\
\hline Anti-nationalism & 83 & 0.77 \\
\hline Anti-war views & 46 & 0.65 \\
\hline Unity & 23 & 0.66 \\
\hline
\end{tabular}

\section{Phase Mapping Statistics}

Table 4 outlines the phase mapping results for frame convergence between the government and the opponents. Matches of frames between the two sides regarding motivation for conflict participation tended to decrease over time. This suggests that communicative steps taken during the conflict to involve the disputants in the decision process, such as public hearings and public discussions, had limited influence. As the stalemate dragged on, dissonance between different interpretations of the issue increased, with a sole exception in phase 5, when frame convergence reached 47 percent. Thus, although the two sides were placed in the same context of policy conflict, the two sides' perceptions of each other's motivations remained divergent and did not move closer to a consensus. Given that the capacity of negotiators is a critical factor

Table 3. Phase-Mapping Results

\begin{tabular}{c|c|c|c}
\hline Phase & Percentage of frame convergence & Number of converging frames & Total frame utterances \\
\hline 1 & 74 & 94 & 127 \\
\hline 2 & 69 & 155 & 224 \\
\hline 3 & 63 & 181 & 287 \\
\hline 4 & 58 & 186 & 321 \\
\hline 5 & 59 & 201 & 340 \\
\hline 6 & 47 & 130 & 276 \\
\hline 7 & 45 & 116 & 257 \\
\hline 8 & 35 & 71 & 204 \\
\hline
\end{tabular}


Table 4. Perception of Other Side's Motivation

\begin{tabular}{c|l|l}
\hline Phase & Dominant frame: government & Dominant frame: opponents \\
\hline 1 & Monetary rewards & Monetary rewards \\
\hline 2 & Monetary rewards & Monetary rewards \\
\hline 3 & Monetary rewards & Land sovereignty \\
\hline 4 & Monetary rewards & Land sovereignty \\
\hline 5 & National interest & Land sovereignty \\
\hline 6 & National interest & Property rights \\
\hline 7 & National interest & Agriculture \\
\hline 8 & National interest & Land sovereignty \\
\hline
\end{tabular}

in managing communication with opponents to settle conflicts, the result provides a significant implication that divergent definitions of the situation will likely lead to intensification of the conflict.

Table 5 compares government negotiators' and opponents' perceptions of the other side's motivations. Consistent with the result found above, the two sides interpreted the issue very differently. Government negotiators referred to monetary rewards and the national interest as the dominant frames for the motivations of opponents, whereas opponents' motivations were not limited to those two. Rather, land sovereignty turned out to be most important frame that accounted for opponents' motivation. Admittedly, during phases 1 and 2 , there was agreement that monetary rewards formed the dominant motivation for conflict participation. Perceptions of motivation also shifted over time. Negotiators' simplistic and stereotypical views of these motivations had a harmful effect on their communications.

Overall, the findings suggest that the communication failure was affected by divergent interpretations of motivation. The diverging points of view were not properly communicated and adjusted, but went unnoticed by both sides throughout the conflict. The multitude of meanings and ever-changing motivations were not well captured by negotiators, and it seems that prolonged conflict and increased social costs drove the negotiators to exert authoritative and physical power over the opponents.

This provides two major implications. First, dialogue for conflict resolution ought to be more than a formal ritual. In making policy decisions, policy makers are prone to defining a situation succinctly rather than acknowledging its complications, because this reduces their workload (March, 1991). Yet, in high-stakes conflict situations, communication ought to be substantive enough to generate a realistic view of the situation (Adams et al, 2003; Fiol, 1994).

Second, prolonged stalemate may result in the situation becoming more complex 
(Neale \& Bazerman, 1985; Nelson, Clawson, \& Oxley, 1997) and thus more difficult to correctly interpret. As shown in table 5, in phase 1 and 2, there were agreements on motivations. If a timely settlement had been reached, it would have forestalled the exacerbation of the conflict caused by the influx of a variety of other participants. But over time, as the conflict began to receive more media attention, a variety of movement groups and individuals began to participate out of solidarity with the opponents. Indeed, in later phases, negotiators faced much more difficulty in dealing with the opposition because of its increased diversity. This is one way that a prolonged stalemate can make a conflict more difficult to resolve.

\section{DISCUSSION}

This study examined how divergent frames for issue interpretation can exacerbate a conflict between the government and opponents by inhibiting the government from effectively managing communication for policy resolution. The analysis showed that, although the government persistently conceived the opponents' motivations as economic, their motivations were in fact far more complex and became more so as more parties joined the opposition. This misconception appears to have made it difficult to achieve agreement between the two parties, and arguably allowed the conflict to intensify over time, eventually leading to physical confrontations. In the eyes of the opponents, the government's simplistic interpretation of the issue was not linked to their perceptions and motivations.

The communicative processes implemented by the government may have been seen as egoistic and authoritative by the opponents, as has been commonly found in other cases of policy conflict in Korea (Jeon, 2001). As evidenced in the findings, the government persistently defined the situation in terms of local or collective self-interestedness that went against the national interest. This definition legitimized the government in exerting physical force as a final option for solution. However, it failed to take into account less obvious symbolic meanings that motivated the opposition (Goffman, 1983; Kubal, 1998). In effect, the government's interpretation of opponents' motivations resulted in increased social costs (Fischer, 2003; Rich, 1989), because the communicative processes were not connected to communication-based resolution of the conflict.

This implies, with regard to policy practice, that a preliminary investigation based on interactive communication with opponents should be regarded as an essential prerequisite for adopting and designing consensus-based strategies for conflict resolution. According to Daft and Weick (1984), scanning and data collection are essential for interpreting the environment and formulating behavior. Information about the situation 
must be obtained, filtered, and processed before choices are made. The quality of action is dependent upon whether the information is consistent with reality (Daft \& Weick, 1984).

The government's initial interpretation of the conflict was based not on substantive investigation, but on the assumption that the opposition was purely economically driven. As the results of this analysis showed, however, opponents had more complicated and intertwined meanings attached to their motivations. To complicate things further, these meanings changed over time. This points to the importance of early and thorough investigation, which could have led to a prompt settlement by making effective communication and reasonable adjustments possible. Previous studies have outlined a set of communicative conflict resolution strategies, including citizen participation, partnering, mediation, outlets for emotions, and joint problem-solving. However, problem definition has gained scant attention in conflict studies (Kim, 2009). As this study demonstrates, it can have a critical effect on the outcome of negotiations.

Given that many policy conflict cases related to development or site selection in Korea failed to be resolved through consensus-based strategies, the design and implementation of these strategies need a critical reappraisal (Jeon, 2001; Kim, 2009; Lee, 1993). Toward this end, this study employed framing analysis to examine how communication failure occurs during interactive processes. It attempted to incorporate framing analysis, which has gained a high degree of popularity in media research (Fiss \& Hirsch, 2005; Nelson, Clawson, \& Oxley, 1997) and social movement studies (Benford, 1997; Benford \& Snow, 2000), into public policy studies of conflict.

The concepts of conflict and resolution are inherently relational, social, and psychological. Nevertheless, framing analysis is rarely used to investigate them (Fischer, 2000, 2003). It is hoped that this study will pave the way to further development of framing analysis in policy studies. In the spirit of a linguistic turn (Alvesson \& Karreman, 2000) of public policy research, this study supports the idea that a rich set of research methods including interpretive modes needs to be adopted as societal problems become more complex and difficult and thus require more down-to-earth understanding.

This study is not without limitations. First, the analysis would be more accurate and rigorous if primary data on the dialogue of the government negotiators and opponents were analyzed instead of text-based secondary data. The secondary data have inherent limitations to their representation of the relationship of interests among the participants. Since they stem mostly from media representations and public statements, they are devoid of the natural language of the participants, which would best represent their genuine intentions and meanings (Crotty, 1998). The use of secondary data was inevitable in this retrospective study and is legitimized by the vast amount of textual sources that were available, including various types of official and unofficial interviews 
with the opponents.

Second, some may argue that the communication breakdown was not an outcome of the government's poor management of consensus-based strategies for conflict resolution, but a strategic choice by the government to legitimize the coercive exercise of physical force. In liberal democratic countries such as Korea, exercising physical force in policy conflict is susceptible to vehement blame from the public. Participatory processes that are designed and implemented in a top-down manner by the government, as in this case, are typically taken as necessary steps for symbolic legitimization (Suchman, 1995). Nevertheless, in this particular case, it seems unlikely that the communication breakdown was a strategic choice by the government, as the conflict dragged on over three years. As time elapsed, a variety of supporters and movement groups participated in the conflict, and these actors comprised a new set of opponents, which made it much harder for the government to settle the dispute. Thus, it seems more reasonable to view the communication breakdown as an outcome of the government's failure to achieve earlier settlement rather than as a planned strategy.

Overall, this study illustrates how divergent interpretations, by government negotiators and opponents, of each other's motivations prevented a settlement of the Daechuri policy conflict. Given that communication- and consensus-based solutions often tend to be ineffective in resolving such conflicts in Korea, it would be meaningful to investigate other similar cases to see if frame divergence is a factor in this ineffectiveness. Further research should be carried out to enrich our understanding of the role of communication and conflict negotiation in this context.

\section{REFERENCES}

Adams, W. M., Brockington, D., Dyson, J., \& Vira, B. 2003. Managing tragedies: Understanding conflict over common pool resources. Science, 302(5652): 19151916.

Ahn, H.-K. 1990. The participation and its patterns in policy process: The Korean case in an age of authoritarianism and modernization. Korean Journal of Policy Studies, 5: 45-52.

Alvesson, M., \& Karreman, D. 2000. Taking the linguistic turn in organizational research: Challenges, responses, consequences. Journal of Applied Behavioral Science, 36(2): 136-158.

Amason, A. C., \& Sapienza, H. J. 1997. The effects of top management team size and interaction norms on cognitive and affective conflict. Journal of Management, 23(4): 495-516. 
Andranovich, G. 1995. Achieving consensus in public decision making: Applying interest-based problem solving to the challenge of intergovernmental collaboration. Journal of Applied Behavioral Science, 31(4): 429-445.

Astley, W. G., \& Zammuto, R. F. 1992. Organization science, managers, and language games. Organization Science, 3(4): 443-460.

Benford, R. D. 1993. Frame disputes within the nuclear disarmament movement. Social Forces, 71(3): 677-701.

1997. An insider's critique of the social movement framing perspective. Sociological Inquiry, 67(4): 409-430.

Benford, R. D., \& Snow, D. A. 2000. Framing processes and social movements: An overview and assessment. Annual Review of Sociology, 26: 611-639.

Bingham, L. B., Nabatchi, T., \& O'Leary, R. 2005. The new governance: Practices and processes for stakeholder and citizen participation in the work of government. Public Administration Review, 65(5): 547-558.

Bogason, P., \& Musso, J. A. 2006. The democratic prospects of network governance. The American Review of Public Administration, 36(1): 3-18.

Braun, V., \& Clarke, V. 2006. Using thematic analysis in psychology. Qualitative Research in Psychology, 3(2): 77-101.

Cacioppo, J. T., \& Berntson, G. G. 1994. Relationship between attitudes and evaluative space: A critical review, with emphasis on the separability of positive and negative substrates. Psychological Bulletin, 115(3): 401-423.

Charalambides, M., Flegkas, P., Pavlou, G., Bandara, A. K., Lupu, E. C., Russo, A., Dulav, N., Sloman, M., \& Rubio-Loyola, J. 2005, June. Policy conflict analysis for quality of service management. Paper presented at Policies for Distributed Systems and Networks, the Sixth IEEE International Workshop.

Corvellec, H., \& Risberg, A. 2007. Sensegiving as mise-en-sens-the case of wind power development. Scandinavian Journal of Management 23(3): 306-326.

Crotty, M. 1998. The foundations of social research: Meaning and perspective in the research process. London: Sage.

Daft, R. L., \& Weick, K. E. 1984. Toward a model of organizations as interpretation systems. Academy of Management Review, 9(2): 284-295.

Drake, L. E., \& Donohue, W. A. 1996. Communicative framing theory in conflict resolution. Communication Research, 23(3): 297-322.

Dutton, J. E., \& Dukerich, J. M. 1991. Keeping an eye on the mirror: Image and identity in organizational adaptation. Academy of Management Journal, 34(3): 517-554.

Edelman, M. 1971. Politics as symbolic action: Mass arousal and quiescence. Chicago: Markham Publishing.

Fiol, C. M. 1994. Consensus, diversity, and learning in organizations. Organization 
Science, 5(3): 403-420.

Fischer, F. 2000. Citizens, experts, and the environment: The politics of local knowledge. Durham, NC: Duke University Press.

2003. Reframing public policy: Discursive politics and deliberative practices. Oxford University Press.

Fiss, P. C., \& Hirsch, P. M. 2005. The discourse of globalization: Framing and sensemaking of an emerging concept. American Sociological Review, 70(1): 29-52.

Fligstein, N. 1997. Social skill and institutional theory. American Behavioral Scientist, 40(4): 397-405.

Folger, J. P., Hewes, D. E., \& Poole, M. S. 1984. Coding social interaction. In B. Dervin \& M. J. Voigt (eds.), Progress in communication sciences. Norwood, NJ: Ablex.

Foreman, P., \& Whetten, D. A. 2002. Members' identification with multiple-identity organizations. Organization Science, 13(6): 618-635.

Gioia, D. A., \& Thomas, J. B. 1996. Identity, image, and issue interpretation: Sensemaking during strategic change in academia. Administrative Science Quarterly, 41: 370-403.

Goffman, E. 1973. The presentation of self in everyday life. Woodstock, NY: Overlook Press.

1974. Frame analysis: An essay on the organization of experience. Boston: Northeastern University Press. . 1983. The interaction order. American Sociological Review, 48: 1-17.

Golden-Biddle, K., \& Rao, H. 1997. Breaches in the boardroom: Organizational identity and conflicts of commitment in a nonprofit organization. Organization Science, 8(6): 593-611.

Hill, V., \& Carley, K. M. 1999. An approach to identifying consensus in a subfield: The case of organizational culture. Poetics, 27(1): 1-30.

Holton, J. A. 2007. The coding process and its challenge. In A. Bryant \& K. Charmaz (eds.), The Sage handbook of grounded theory. Thousand Oaks, CA: Sage Publications.

Hong, Y.-D. 2012, February 21. Paradox of hope. Hangyurae.

Hsieh, H.-F., \& Shannon, S. E. 2005. Three approaches to qualitative content analysis. Qualitative Health Research, 15(9): 1277-1288.

Imperial, M. T. 2005. Using collaboration as a governance strategy: Lessons from six watershed management programs. Administration and Society, 37(3): 281-320.

James, W. 1950. Principles of psychology (Vol. 2). New York: Dover Publications.

Jeon, J.-S. 2001. Analysis on the conflicting points of the locational conflict. Korean Journal of Policy Studies, 15(2): 101-115. 
Kim, H. 2009. The process of conflict resolution in public project disputes: Analysis by settlement methods. Korean Journal of Policy Studies, 23(2): 147-170.

Kubal, T. J. 1998. The presentation of political self: Cultural resonance and the construction of collective action frames. Sociological Quarterly, 39(4): 539-554.

Lee, S. H. 1993. Policy conflict and its settlement in Korea: The case of regulatory reform. Korean Journal of Policy Studies, 8: 33-57.

Levi-Strauss, C. 1974. Structural anthropology. Basic Books.

Luhmann, N. 1995. Society and interaction. In Social Systems. Stanford, CA: Stanford University Press.

2000. Familiarity, confidence, trust: Problems and alternatives. Department of Sociology, University of Oxford, Oxford, UK. Available from http://www .sociology.ox.ac.uk/papers/trustbook.html.

March, J. G. 1991. Exploration and exploitation in organizational learning. Organization Science, 2(1): 71-87.

McBeth, M., \& Shanahan, E. 2004. Public opinion for sale: The role of policy marketers in Greater Yellowstone policy conflict. Policy Sciences, 37(3): 319-338.

Miller, M. M. 1997. Frame mapping and analysis of news coverage of contentious issues. Social Science Computer Review, 15(4): 367-378.

Moe, R. C. 2001. The emerging federal quasi government: Issues of management and accountability. Public Administration Review, 61(3): 290-312.

Moynihan, D. P., \& Pandey, S. K. 2008. The ties that bind: Social networks, personorganization value fit, and turnover intention. Journal of Public Administration Research and Theory, 18(2): 205-227.

Neale, M. A., \& Bazerman, M. H. 1985. The effects of framing and negotiator overconfidence on bargaining behaviors and outcomes. Academy of Management Journal, 28(1): 34-49.

Nelson, P., \& Brown, J. L. 1993. Analyzing communication in and around organizations: A critical hermeneutic approach. Academy of Management Journal, 36(6): 1547-1576.

Nelson, T. E., Clawson, R. A., \& Oxley, Z. M. 1997. Media framing of a civil liberties conflict and its effect on tolerance. American Political Science Review, 91(3): 567-583.

O’Reilly, C. A., Caldwell, D. F., \& Barnett, W. P. 1989. Work group demography, social integration, and turnover. Administrative Science Quarterly, 34(1): 21-37.

Park, C.-M. 1991. Authoritarian rule in South Korea: Political support and governmental performance. Asian Survey, 31(8): 743-761.

Perloff, J. M., \& Persons, J. B. 1988. Biases resulting from the use of indexes: An application to attributional style and depression. Psychological Bulletin, 103(1): 
95-104.

Provan, K. G., \& Kenis, P. 2008. Modes of network governance: Structure, management, and effectiveness. Journal of Public Administration Research and Theory, 18(2): 229-252.

Quirk, P. J. 1989. The cooperative resolution of policy conflict. American Political Science Review, 83(3): 905-921.

Rich, M. J. 1989. Distributive politics and the allocation of federal grants. American Political Science Review, 83(1): 193-213.

Rouleau, L. 2005. Micro-practices of strategic sensemaking and sensegiving: How middle managers interpret and sell change every day. Journal of Management Studies, 42(7): 1413-1441.

Rumsfeld, D. H. n.d. Positioning America's forces for the 21st century. Washington, DC: US Department of Defense.

Sewell, W. H., Jr. 1997. Geertz, cultural systems, and history: From synchrony to transformation. Representations, 59: 35-55.

Smircich, L. 1983. Organizations as shared meanings. In L. R. Pondy, P. Frost, G. Morgan, \& T. Dandridge (eds.), Organizational symbolism. Greenwich, CT: JAI Press.

Suchman, M. C. 1995. Managing legitimacy: Strategic and institutional approaches. Academy of Management Review, 20(3): 571-610.

Suddaby, R., \& Greenwood, R. 2005. Rhetorical strategies of legitimacy. Administrative Science Quarterly, 50(1): 35-67.

Tucker, L. R. 1998. The framing of Calvin Klein: A frame analysis of media discourse about the August 1995 Calvin Klein jeans advertising campaign. Critical Studies in Mass Communication, 15(2): 141-157.

Weick, K. E. 1988. Enacting sense making in crisis situations. Journal of Management Studies, 25: 305-317.

1993. The collapse of sensemaking in organizations: The Mann Gulch disaster. Administrative Science Quarterly, 38(4): 628-652.

Williams, D. R., Patterson, M. E., Roggenbuck, J. W., \& Watson, A. E. 1992. Beyond the commodity metaphor: Examining emotional and symbolic attachment to place. Leisure Sciences: An Interdisciplinary Journal, 14(1): 29-46.

Wilson, M. A. 1997. The wolf in Yellowstone: Science, symbol, or politics? Deconstructing the conflict between environmentalism and wise use. Society \& Natural Resources, 10(5): 453-468.

Yoo, Y.-W. 2006, May 4. Daechuri compensation amounts to five hundred thirty million won on average. Chosun Ilbo. 